Bol. Acad. peru. leng. 51. 2011 (221-237)

\title{
A VUELTAS CON LOS AUTORES DEL LAZARILLO DE TORMES (A PROPÓSITO DEL LIBRO DE MERCEDES AGULLÓ)
}

\author{
Fernando Rodríguez Mansilla \\ Hobart and William Smith Colleges
}

Fecha de recepción:

$10 / 12 / 2010$

Fecha de aceptación:

$25 / 02 / 2011$

A la memoria de Luis Jaime Cisneros

En los últimos años se ha vuelto frecuente que los medios de comunicación anuncien que acaba de descubrirse al "verdadero" autor del Lazarillo de Tormes. Igual que las predicciones anuales que nadie recuerda, este tipo de noticia también acaba cayendo en el olvido. Las nuevas propuestas de autor para el Lazarillo aseguran para el catedrático una fama de quince minutos a través de entrevistas en prensa. No obstante, ninguna de estas propuestas ha logrado consolidarse entre los especialistas, quienes son los únicos que pueden efectivamente evaluar los resultados y considerar si resultan solventes o no.

El más reciente "verdadero" autor del Lazarillo, Diego Hurtado de Mendoza, fue proclamado por todo lo alto en los periódicos más respetables del mundo iberoamericano. Esta vez, la atribución corre a 
cargo de Mercedes Agulló, historiadora experta en archivos y fondos documentales del Siglo de Oro. Tras leer su libro A vueltas con el autor del Lazarillo. Con el testamento y el inventario de bienes de don Diego Hurtado de Mendoza, este filólogo se ve en la obligación de echar una mirada crítica al estudio y, a propósito de este, a las atribuciones recientes que ha sufrido el texto del Lazarillo.

\section{Rosa Navarro y Alfonso de Valdés}

La década que ya cerramos ha visto la recuperación de la autoría del Lazarillo como tema de debate intenso, tras un relativo silencio de varias décadas. Una revisión del siempre útil Catálogo bibliográfico de la literatura picaresca. Siglos XVI-XX de Joseph L. Laurenti arroja que en las últimas décadas muy ocasionalmente aparecía un artículo que, sin hacer grandes olas, aportaba nuevos datos a favor de uno u otro candidato, pero sin la energía afirmativa con que recientemente se han venido postulando autores. El asunto de la autoría había quedado bastante relegado como tema dentro de la crítica lazarillista hasta que Rosa Navarro volvió a traerlo a primer plano con su estudio Alfonso de Valdés, autor del "Lazarillo de Tormes", publicado originalmente en 2003. Este libro no solo es el primero de la década, sino que es, de lejos, el principal, en la medida en que impuso una forma de leer el texto y postular, a través de tal lectura, la figura del autor. La profesora Navarro desarrolla una compleja hipótesis que se basa en unos supuestos (verbigracia: la pérdida de una primera página en el texto del Lazarillo, un indemostrable alcoholismo del arcipreste de San Salvador, etc.) cuya verificación presenta gran dificultad y, por otro lado, en una larga lista de concordancias léxicas. En principio, existe el problema de que Alfonso de Valdés murió en 1532, por lo que Navarro queda obligada a fechar el Lazarillo tempranamente, desatendiendo todos los elementos que indicarían una composición bastante posterior. En torno a las concordancias aportadas, que alcanzan casi el centenar, estas revelarían las "lecturas" de Alfonso. Pero dichas "lecturas" se deducen de los gustos de su hermano Juan, manifiestos en el Diálogo de la lengua. Si bien eran gemelos, cabe discutir si compartían necesariamente las mismas preferencias literarias. Además, ¿cómo discriminar las concordancias 
debidas a un mismo acervo cultural frente a las realmente pertinentes? El criterio de Navarro en este caso es la cantidad más que la calidad de sus hallazgos. Quizás el argumento más fuerte contra la atribución sea el del perfil literario de Alfonso, ducho en la escritura de diálogos a la manera erasmista, pero ¿cómo explicar la experimentación narrativa que implicaría el Lazarillo en el oficio literario de Valdés? Hay un salto que queda sin explicar. ¿Cómo el autor pudo pasar de componer dos diálogos con deudas literarias notables y expresas a un texto sin precedentes tan diáfanos? Es una pregunta que Navarro no puede responder cabalmente en ninguna parte de su libro.

El estudio de Rosa Navarro es emblemático del método para proponer autores del Lazarillo y cabe reconocer que lo aplica con una maestría que se echa en falta generalmente en las otras investigaciones que siguen su estela. Una de las particularidades del método, que constituye a mi parecer uno de sus puntos flojos, es que descarta tomar en cuenta documentos ya conocidos, pero además no se preocupa por presentar nuevos, porque no los hay o porque se ha abandonado el trabajo de archivo. En segundo lugar, se extraña en este tipo de análisis de identificación autorial un examen estilístico profundo. El estilo no es solo el empleo de refranes (no hay escritor aurisecular que no los use) o determinadas frases hechas (que son eso, frases ya fosilizadas en la mente de los hablantes): el estilo es, en el Lazarillo de Tormes, ante todo la sintaxis, o sea el orden en que tales palabras, que son patrimonio común, se disponen para formar oraciones. Así, una lista de "concordancias léxicas" no arroja como resultado el estilo propiamente dicho del autor. La mejor muestra de la vacuidad de tales concordancias es que las mismas pueden esgrimirse a favor de un candidato como de otro. Si se cotejan los pasajes que presenta el estudio de Navarro sobre Valdés con los que ofrece el estudio de Francisco Calero sobre Vives (que examinaremos a continuación) se observará que una gran cantidad de concordancias se repite. Los mismos datos pueden usarse para un autor como para el otro. El catálogo de pasajes paralelos, si se lleva a cabo con inteligencia, revela en todo caso una tradición literaria y folclórica común, pero no es suficiente para atribuir una influencia o para determinar que pertenecen al mismo autor. Precisamente en uno de sus trabajos más 
celebrados, Marcel Bataillon apelaba a la necesidad de controlar este fondo común de las obras auriseculares, pero para iluminar aspectos de la construcción de personajes y episodios o las connotaciones que pueden adoptar diversos elementos narrativos, ya que de esto se trata, indagar por el "sentido literal" que intenta aclarar la filología en su vena más enriquecedora (Bataillon 17).

Como las concordancias intentan convencer más por cantidad que por calidad y su recolección no exige mayor discernimiento, se elaboran hipótesis novelescas en torno a situaciones inverosímiles e incluso improbables: imaginar que "vuestra merced" es una mujer no deja de ser una idea sugestiva, pero carece del más mínimo respaldo textual; afirmar que Alfonso de Valdés fue tan sagaz que intentó hacer invisibles sus lecturas para componer el Lazarillo; presentar una cantidad enorme de concordancias que las revelarían. Leer un estudio así deja la impresión de que el Siglo de Oro español era muy cercano a una novela de Dan Brown. Y entonces, a la luz de este tipo de investigación, la filología queda reducida a un juego de detectives inofensivos.

\section{Francisco Calero y Juan Luis Vives}

Menos atención ha recibido la atribución que, por los años en que Navarro publicó sus hallazgos, ha ido esbozando Francisco Calero, quien presenta a Juan Luis Vives como el legítimo autor del Lazarillo. Calero apela al mismo método de pasajes paralelos, que él denomina "concordancia de pensamientos", pero a través de una mediación. Calero ha atribuido primero a Vives el Diálogo de Mercurio y Carón así como el Diálogo de las cosas acaescidas en Roma de Alfonso de Valdés (con lo que el aporte literario del conquense a la literatura española ha quedado completamente eliminado) y con ello le ha bastado apoyarse en una buena parte de los argumentos de Rosa Navarro, transfiriendo las concordancias de Valdés hacia Vives. De tal forma, a la vez que desestima el trabajo de Navarro, se aúpa sobre sus hombros.

El estudio del profesor Calero no ha recibido casi ninguna atención en los círculos académicos, tal vez porque se trata de un discreto 
profesor de lenguas clásicas, afiliado a una universidad con mucha menos proyección que la de Barcelona y sin una red de contactos y cajas de resonancia en los medios de comunicación. En realidad, el trabajo de Calero, en esencia, no es menos inconsistente que el de Navarro, ya que comparten los mismos principios de análisis, solo que aplicados a distintos personajes.

Hay que señalar, eso sí, que la metodología aplicada lleva al lector a preguntarse, mientras revisa el estudio, qué es un trabajo de investigación. Una hipótesis arriesgada, sin ningún apoyo documental, y una acumulación de pasajes paralelos que cubren alrededor del $70 \%$ de la extensión total del volumen. Y, claro, la mayoría de ellos son lugares comunes de la tradición cultural europea (verbigracia: comparar al rey con un pastor o el cuerpo como cárcel del alma) o sátira anticlerical que era santo y seña entre los espíritus ilustrados de la época (¿qué humanista no hubiera comulgado con esa actitud espiritual presente en el Lazarillo?). De tal forma, en lo que supondría la parte más sólida de su argumentación, Calero encuentra coincidencias ideológicas entre los textos valdesianos, los de Vives, compuestos en latín, y el Lazarillo. Nuevamente, dichas coincidencias no son lo suficientemente rotundas como para no poder explicarse por influencias de terceros (el Asno de oro, la sátira lucianesca, etc.). La muerte de Vives en 1540 trae consigo el problema de la fecha de redacción del Lazarillo, que los estudios más sólidos remiten a unos años más tarde.

Los trabajos de Calero revelan las limitaciones más serias que ofrece el método de atribución que se viene practicando: no existe ningún análisis de la construcción narrativa ni de sus elementos. ¿Dónde queda el arte de la elaboración de un texto ficcional? ¿Qué tiene de singular el estilo de Vives o el de Valdés (aparte de las manidas concordancias que se pueden achacar ora a uno ora al otro) que se encuentre también en el texto del Lazarillo? Ante la imposibilidad de abordar cuestiones tan complejas como estas, concernientes al tejido textual propiamente dicho, Calero apela a los mismos argumentos extravagantes de Rosa Navarro, pero sin la fineza retórica que esta emplea. Un botón: para desestimar a Valdés como autor potencial de una obra literaria más que buena se 
emplea un argumento curioso. Según Calero, si el Diálogo de Mercurio y Carón es una obra maestra (lo cual es discutible, no es mejor que el Viaje de Turquía o el Crótalon) debió ser escrito por un "gran autor", pero, siempre según Calero, Valdés no puede serlo porque era mal latino, a lo cual agrega esta afirmación muy discutible: "Se podrá decir que Alfonso podía ser mediocre latinista y un excelente escritor en castellano, pero esto no es normal, ya que las personas verdaderamente bilingües escriben bien o mal en ambas lenguas" (21-22). ¿Qué tiene que ver con su destreza literaria el hecho de que Valdés tenga conocimientos óptimos o pésimos del latín? Nadie duda de que Quevedo es un magnífico escritor, pero sus conocimientos del latín, de los que se preciaba lo suficiente para traducir citas de Petronio, deja muchísimo que desear (traduttore, traditore), tal como lo ha revelado un esclarecedor artículo de Julio Picasso Muñoz.

\section{José Luis Madrigal y Francisco Cervantes de Salazar}

Una mención aparte merece el trabajo de atribución de José Luis Madrigal sobre Francisco Cervantes de Salazar, discípulo del humanista, de filiación erasmiana, Alejo de Venegas. Menos popular que Vives, aunque quizás tan conocido como Valdés, la figura de Cervantes de Salazar resulta atractiva dentro de la intelectualidad de la época. Discípulo de Venegas en Toledo y luego estudiante en Salamanca (dos ciudades que son referentes claves del Lazarillo), fue catedrático en Osuna y luego emigrado a México, donde contribuye a la creación de la Universidad y se convierte en cronista de Indias, además de gozar de la amistad de Hernán Cortés.

Madrigal es mesurado en el tono de su estudio, plenamente conciente de que aplica un método que consiste en leer entre líneas, por lo que el crítico se convierte en un detective: "Cualquier atribución tiene mucho de labor detectivesca, de tal manera que si queremos coronar con éxito las pesquisas, debemos, a lo Sherlock Holmes, seguir un método de inducción lógica a partir de los datos que conocemos”. Quizás por esta plena conciencia de la naturaleza de su trabajo, Madrigal sí reflexiona sobre los pasajes paralelos escogidos, analizándolos y captando los matices entre ellos. En comparación con Navarro y Calero, Madrigal es mucho 
más racional frente a su objeto de estudio, sin dejarse llevar por la pasión en torno al autor elegido: evalúa, discrimina y selecciona. Sin duda, dota al método de un carácter más científico. Cuando busca semejanzas estilísticas, basadas en construcciones sintácticas, entre Cervantes de Salazar y el Lazarillo, lo hace descartando aquellas que se repiten en obras de terceros autores, para que no exista la sospecha de la mera coincidencia (que siempre asoma en las candidaturas de Vives y Valdés). Su corpus de textos de descarte es amplio y va desde La Celestina hasta La gitanilla de Cervantes. De esta forma, el examen de Madrigal aplica una versión mucho más seria y precisa del método que emplea Rosa Navarro y del cual abusa Calero, sin embargo no ha obtenido la atención merecida.

\section{Juan de Timoneda y la conjura castellana}

La atribución más llamativa con la que contamos, dadas sus connotaciones extraliterarias, es la de Juan Timoneda, planteada por Jordy Bilbeny ${ }^{1}$. Según el investigador, el Lazarillo de Tormes sería la traducción al castellano de un libro originalmente escrito en valenciano, La vida de Llàtzer de Tormos. Sostiene que muchas de las incoherencias del texto (como un presunto desconocimiento de la geografía castellana) se explicarían por tratarse de una versión traducida que tuvo que cambiar los nombres de lugares: las acciones realmente se llevarían a cabo entre Valencia y Gandía, cerca de la villa de Tormos. Asimismo, encuentra en la prosa y la sintaxis algunos rasgos que permitirían afirmar un origen extranjero, pues el texto contendría, siempre según Bilbeny, una gran cantidad de catalanismos. La autoría de Timoneda se sostiene, entre otras razones, teniendo en cuenta que en una de sus obras, el Menechmos, hay un personaje definido como "hermano de Lazarillo de Tormes", pero más que nada por el hecho de ser un autor de oficio y bilingüe, que escribe tanto en valenciano como en la lengua de Castilla. El trabajo de Bilbeny, al margen de los circuitos académicos convencionales, tiene difusión mayormente en internet y adopta una postura contracultural que se inserta en cierta vertiente del nacionalismo catalán, la cual

1 Extraigo la noticia de Néspolo, Matías. "El Lazarillo es de autor valenciano". El Mundo. Sección Cultural. 16 de noviembre de 2007. 
intenta demostrar la existencia de una conspiración histórica tramada desde el inicio de la Edad Moderna por el reino de Castilla. Se trataría de una conjura que ha buscado sistemáticamente opacar lo catalán y subyugar a la cultura catalana. Dentro de esta tarea de desmontaje del gran complot castellano es necesario identificar a todos los personajes que, en realidad, eran catalanes y cuyo origen fue silenciado: Cristóbal Colón, Garcilaso de la Vega, el propio Miguel de Cervantes...

Indudablemente, este es el rostro más patético de la filología, el de la manipulación de un objeto cultural prestigioso de talla universal, como el Lazarillo de Tormes, con fines políticos. Dentro de la teoría de la conspiración, suma de todas las paranoias, que elaboran Bilbeny y sus seguidores, se postulan las hipótesis más desopilantes, como que $\mathrm{La}$ Celestina fue escrita en valenciano. Precisamente uno de los caballos de batalla de esta clase de nacionalismo catalán es demostrar que las grandes obras literarias castellanas fueron escritas en valenciano o catalán, pero que este origen foráneo fue ocultado por la Corona, en coalición con la Iglesia, eliminando todos los testimonios que lo podrían demostrar. Estos trabajos carecen de respaldo textual alguno (o si dicen tenerlo, leen los textos a capricho, con ignorancia), ni mucho menos presentan mayor rigor crítico ni científico. No obstante, poseen un valor anecdótico que refleja los límites a los que ha llegado la fiebre del fetichismo autorial, puesta aquí al servicio de causas absolutamente extraliterarias. Lo que menos les interesa a Bilbeny y compañía, no cabe duda, es el texto del Lazarillo.

\section{La novedosa antigüedad de Hurtado de Mendoza}

La atribución del Lazarillo a Diego Hurtado de Mendoza (15031575) se gestó tempranamente, ya en el siglo XVII. El problema con esta atribución hasta ahora es que no ha contado con otro respaldo que no sea la fama casi proverbial de Hurtado como sujeto donairoso, sustentada en buena medida por su poesía jocosa. Una fama tal que dio pie a atribuirle no solo el Lazarillo sino otras obras anónimas de corte divertido y procaz de su época. En ese sentido, se inserta en la misma línea de especulaciones autoriales surgidas en el Siglo de Oro, de tinte folclórico, que fueron moneda corriente por entonces, como aquella, 
nacida en Inglaterra, que sostenía que el Lazarillo fue compuesto por unos obispos españoles camino de Trento; o la que afirma que el libro se debe a seis pícaros que lo escribieron en solo dos días, según la recoge una pieza de teatro breve hacia mediados del XVII.

El vacío documental en torno a esta atribución intenta ser cubierto, aunque infructuosamente a nuestro parecer, por el libro de Mercedes Agulló y Cobo, A vueltas con el autor del Lazarillo. La historiadora ha encontrado un documento inédito y lo esgrime como prueba de la autoría de Mendoza. Dicho documento es la relación de bienes que dejó al morir en 1599 Juan de Valdés, abogado de los reales consejos de Madrid. En este inventario se incluyen libros y documentos que le legó a Valdés el cosmógrafo y cronista mayor de Indias Juan López de Velasco, quien tuvo a su cargo la censura del Lazarillo, las obras de Cristóbal de Castillejo y la Propalladia de Bartolomé de Torres Naharro. López de Velasco a su vez había sido el testamentario de Diego Hurtado de Mendoza a la muerte de este en 1575, por lo cual a fines del XVI el abogado Valdés acaba reuniendo en su biblioteca parte del inmenso legado bibliográfico de Mendoza. Conciente de este patrimonio, Valdés tuvo el cuidado de inventariar todo lo que recibió como herencia de Velasco clasificándolo en cajones. Precisamente, en la detallada relación de tales documentos que poseía el abogado se cuenta que en el sexto cajón de papeles, se encontraba "un legajo de correciones hechas para la impresión de Lazarillo y Propaladia” (cit. en Agulló y Cobo 37). Este legajo, que sería el texto base de la edición castigada del Lazarillo de Tormes y la obra dramática de Torres Naharro, se hallaba en uno de los cajones que contenían documentos del fondo bibliógrafico de Mendoza. Así, a su lado se encontraban, según reza el inventario, un manuscrito de la Rebelión de los moriscos de Granada, y otros papeles indudablemente mendocinos, como sus numerosas cartas. A partir de este hallazgo, pero sobre todo dada la proximidad de unos documentos con otros, Agulló relanza la hipótesis de la autoría de Mendoza, aunque seguimos moviéndonos en el marco de ideas y supuestos que no pueden verificarse: ¿qué hacía ese legajo de correcciones entre los papeles de Mendoza? ¿Acaso López de Velasco usó un manuscrito que le proveyó el poeta granadino e intentaba restituírselo? 
Agulló empieza a hacerse preguntas que intentan provocar en el lector la sensación de que Hurtado de Mendoza podría ser el autor del Lazarillo, leyendo entre líneas a López de Velasco y la misma historia de Lázaro. Así, Agulló se pregunta cómo podía el censor afirmar, en la advertencia al lector que incluye en su edición del Lazarillo castigado, (1573) que, el autor de la segunda parte, calificada como "impertinente y desgraciada”, no lo era también de la primera. Para la estudiosa, Velasco solo podía afirmarlo si sabía que se trataba de su amigo Mendoza. Ante este argumento, cabría señalar que López de Velasco está expresando una opinión basada en su propio juicio literario: la superioridad del Lazarillo original frente a la segunda parte de 1555, la cual no gozó del mismo aprecio, reflejado en reediciones, que la primera. Si se lee con atención el preliminar velasquiano se percibe que este ofrece la edición como un relanzamiento editorial que intenta cubrir un vacío que estaba siendo cubierto por otras ediciones publicadas fuera de la península, pero que ingresaban de contrabando, con grave perjuicio de la moral de los católicos lectores españoles:

[El Lazarillo] fue siempre a todos muy adepto; de cuya causa, aunque estaba prohibido en estos reinos, se leía y imprimía de ordinario fuera dellos. Por lo cual [...] se emendó de algunas cosas por que se había prohibido y se le quitó toda la segunda parte, que por no ser del autor de la primera, era muy impertinente y desgraciada. (cit. en Caso González 19)

En ese contexto, la comparación con la segunda parte del Lazarillo, una fantasía lucianesca publicada en Amberes, configura ante todo un reclamo para el lector entendido. Es conveniente evaluar con cuidado la información que sobre una obra literaria presentan los preliminares impresos, que a menudo ponen de manifiesto una estrategia comercial. En 1587, la edición del Lazarillo publicada en Milán sostiene prácticamente todo lo contrario a lo afirmado por Velasco respecto de la difusión del texto. Para el editor Antonio de Antoni, la novela del Lazarillo está "ya casi olvidada y de tiempo carcomida" (cit. en Caso González 20) y no tiene problema alguno en publicarla junto a la segunda parte de Amberes. La justificación del librero italiano para publicar este 
volumen doble es otra: ofrece al lector una obra de mérito que se precia de haber rescatado, de la mano de otra, la segunda parte anónima, en torno a cuya autoría no para mientes. En cambio, López de Velasco tiene que argumentar que la novela está circulando profusamente sin el debido control para justificar esta edición censurada, cuya calidad enaltece comparándola con la segunda parte.

Las demás pruebas que aporta Agulló para defender la autoría de Mendoza configuran lo que en la investigación judicial se conoce como pruebas circunstanciales. Encontrar en un cajón las correcciones al Lazarillo y la Propalladia que hizo Velasco entre documentos fidedignos de Mendoza no pasa de ser una coincidencia dentro de una lista de las mismas que intenta elaborar la investigadora ante la falta de mayores pruebas comprometedoras. Es innegable que el perfil intelectual y literario de Hurtado de Mendoza lo ha mantenido desde siempre entre los candidatos más fuertes a la paternidad del Lazarillo de Tormes. Lo que ha hecho Agulló es revitalizar una opinión que, desde Ángel González Palencia, pasando por Luis Jaime Cisneros y Marcel Bataillon, hasta Francisco Rico, a quien debemos la edición prácticamente definitiva del Lazarillo, se ha vuelto un lugar común de la crítica: no hay nada que pueda objetar la candidatura de Hurtado de Mendoza (como sí ocurre con otros candidatos, como el tan mentado últimamente Alfonso de Valdés), pero tampoco se ha aportado ninguna prueba concluyente que la impulse más allá de la simpatía que su figura provoca ${ }^{2}$. La mención de un manuscrito corregido del Lazarillo entre los papeles que alguna vez pertenecieron a Hurtado de Mendoza, documentos todos que pueden haber llegado allí, juntos, de muchísimas maneras, carece de la rotundidad necesaria.

2 Simpatía de la que daba fe, en 1946, la edición del Lazarillo de Luis Jaime Cisneros, quien, contra el juicio de Julio Cejador, rompió una lanza por Diego Hurtado de Mendoza en una época en que su candidatura había perdido terreno frente a las de Sebastián de Horozco, el bachiller Pedro de Rhúa o el propio Lope de Rueda. Los argumentos de Cisneros, sin otro propósito que estimular el debate crítico, fueron lo suficientemente persuasivos para merecer la aprobación del "príncipe de los hispanistas", Marcel Bataillon. 
El grueso de los datos y argumentos proveídos por la autora, en ese aspecto, no son novedosos. Tales "coincidencias y entreveros [que] apuntan a don Diego como 'padre' de Lázaro" (46) no son más que eso, hechos azarosos. Que Lázaro diga que su madre empezó a trabajar para los mozos del Comendador de la Magdalena y que, por otra parte, Hurtado de Mendoza hacia 1552 fuese nombrado comendador de orden de Calatrava, bajo cuya jurisdicción se hallaba aquella iglesia de la Magdalena en Salamanca (Agulló 50) son dos hechos que no presentan vínculo alguno, salvo el que la sugestión de la autora puede promover. Más débil resulta el argumento resultado de leer entre líneas el final del Lazarillo de Tormes. ¿Por qué atribuir a Hurtado de Mendoza la afirmación del protagonista del libro cuando declara hallarse "en la cumbre de toda buena fortuna"? (Agulló 52). Precisamente uno de los logros formales del Lazarillo es mantener una uniformidad de la voz narrativa desde el inicio hasta el fin del relato, pese a las chapuzas que sufrió al pasar por la imprenta (donde se acuñó el título de la obra, la división en prólogo y "tractados", así como los títulos internos): la misma voz que habla sobre el "caso" en el prólogo es la que vuelve a referirse al "caso" al final del libro.

Al tratar de emitir un juicio objetivo en torno al estudio de Mercedes Agulló, habría que declarar que el mérito del trabajo no se encuentra en la postulación de Hurtado de Mendoza como autor del Lazarillo, dado que la argumentación es endeble, la gran y única prueba documental esgrimida no convence y los argumentos que se plantean alrededor de ella no dejan de sustentarse en el azar. El más destacable logro del trabajo de Mercedes Agulló consiste en refrescarnos la imagen de don Diego y en invitarnos a meditar en torno a uno de los personajes más interesantes del humanismo y la nobleza española del siglo XVI. Por esa razón, nos parece que el título del libro está desenfocado o bien obedece a una estrategia de ventas, tal como la que aplicaban los editores áureos: mentar el Lazarillo de Tormes en el título del libro atrae muchísimos más lectores que mencionar tan solo a Hurtado de Mendoza, nombre conocido solo entre especialistas.

Una muestra de que la autoría del Lazarillo no es, precisamente, el gran aporte del libro es que Agulló no destina más de ocho páginas (de 
la página 44 a la 52) a ocuparse de defender la candidatura de Hurtado. A vueltas con el autor del Lazarillo. Con el testamento y el inventario de bienes de don Diego Hurtado de Mendoza posee ciento cuarenta páginas, con lo cual el asunto de la autoría del granadino no consume más del 10\% del volumen. El aporte concreto de Agulló a la crítica aurisecular, a nuestro parecer, es el que enuncia el subtítulo del libro. Dando fe de su larga experiencia como historiadora y eximia especialista en documentos históricos, presenta una transcripción del riquísimo inventario de los objetos y fondos bibliográficos que configuraron el legado de don Diego. En ese sentido, el libro de Agulló ofrece datos de suma relevancia para los estudios de cultura material renacentista y para la historia del libro. Pero esto, que le otorga a la investigación un valor per se, no tiene nada que ver con la atribución del Lazarillo, la cual a fin de cuentas, tras culminar la lectura crítica del libro, da la impresión de ser totalmente incidental, pese a los esfuerzos de la prensa y la publicidad en torno al lanzamiento del volumen.

\section{Conclusión}

Si bien el trabajo de Agulló no sigue el mismo método de especulación que abrazan los estudios de atribución aplicados al Lazarillo desde el trabajo de Rosa Navarro, sí es tributario de su afán de dar por sentados hechos que no resisten una verificación. No es posible que el fetichismo autorial (la obsesiva búsqueda de un nombre al que asociar con un clásico como el Lazarillo) haya triunfado por encima de las evidencias textuales y la reflexión respaldada por la teoría literaria ${ }^{3}$.

3 Súmese a estos despropósitos el desmesurado interés, que raya en chovinismo, de ciertas instituciones locales en España que, en su afán de exaltar lo propio, estimulan los estudios de autoría sin percatarse de sus debilidades. No es de extrañar, por eso, que la atribución de Valdés (notable conquense) haya contado con el entusiasmo de la Excelentísima Diputación de Cuenca, que publicó la primera edición del estudio de Rosa Navarro o el Ayuntamiento de Valencia, que ha respaldado las investigaciones de Luis Calero concernientes a Juan Luis Vives como autor de obras como el Diálogo de Mercurio y Carón y el Lazarillo de Tormes. Ni que decir que las ideas de Bilbeny y sus adláteres son auspiciadas por entornos políticos a los que convienen tales hallazgos, por estrambóticos que resulten. 
Estos estudios en torno a la autoría del Lazarillo nos deben llevar a reflexionar en torno a lo poco que conocemos sobre el panorama cultural real del Siglo de Oro. Aunque a veces son impulsivos y otras están cargados de apriorismos, estos trabajos aportan ciertos beneficios colaterales, en la medida en que no figuran dentro de sus propósitos primarios. Por ejemplo, aunque de forma oblicua, se vuelve a discutir la datación del Lazarillo. A estas alturas, es posible afirmar, considerando todo lo que se ha espigado, una redacción tardía del texto, o sea bien próxima al año de publicación del primer testimonio conocido (1554). Otro beneficio es que conocemos más del ambiente intelectual que rodeó la creación del Lazarillo de Tormes y con ello la de toda literatura española de la primera mitad del XVI: se ha revelado un sinnúmero de ecos literarios y tradicionales en el texto de Lázaro y se investiga más en torno a la espiritualidad que emana de su historia.

Establecer la autoría del Lazarillo de Tormes puede efectivamente arrojar nuevas luces sobre diversos aspectos de la obra. No obstante, a diferencia de otros libros, el Lazarillo no demanda por sí mismo un autor identificable. No se trata de un texto del cual hayamos perdido ese dato, sino que más bien existía una intención autorial de desvanecimiento, de cederle ese privilegio de "autor" al propio Lázaro, protagonista y escritor de su propia vida. No puede entenderse de otra forma el enfático "Yo" con el que arranca el Lazarillo, con un prólogo asumido por el propio personaje. Cabría recordar el afortunado aserto de Américo Castro: "El autobiografismo del Lazarillo es solidario de su anonimato" (145). El libro se plantea frente al lector como el relato de la vida de un humilde pregonero toledano llevado a cabo por él mismo. Para que esa superchería funcionara, para que la ficción se desatara eficientemente, el autor "real" debía desaparecer de la escena. El anonimato, de tal forma, supone una necesidad estructural. Era pretensión de ese anónimo autor que la gente asumiera el texto como escrito realmente por Lázaro de Tormes, al menos dentro de las convenciones que regían la ficción. Diríase que el reconocimiento o fama asociados con la autoría no eran pretendidos por quien compuso el Lazarillo.

En ese misma vía de razonamiento, ¿por qué creer que el autor del Lazarillo debió ser necesariamente un escritor profesional o al 
menos alguien que después publicó sus obras con nombre y apellido? Más verosímil resulta, tras observar la compleja ideología que postula el Lazarillo, la idea de un moralista encubierto, un humanista que fue "novelista de una sola novela", como gusta caracterizar Antonio Rey Hazas al tipo de escritor que abraza el género picaresco (13). Por todo ello, el Lazarillo de Tormes se ha preservado como un prodigio independiente que no ha requerido el esclarecimiento de la identidad de su verdadero autor para reconocer en el texto el arte de un hábil narrador que prefirió darle el protagonismo absoluto a Lázaro, un don nadie, como auténtico "autor" de su propia vida. 


\section{BIBLIOGRAFÍA}

AGUlLÓ Y COBO, Mercedes. A vueltas con el autor del Lazarillo. Madrid: Calambur, 2010.

BATAILLON, Marcel. Défense et illustration du sens littéral. Manchester: Modern Humanities Research Association, 1967.

CALERO, Francisco. Juan Luis Vives, autor del Diálogo de Mercurio y Carón. Valencia: Ajuntament de Valencia, 2004.

. "Luis Vives fue el autor del Lazarillo de Tormes". Espéculo 32 (2006). http://www.ucm.es/info/especulo/numero32/ luvives.html

CASO GONZÁLEZ, José. La vida de Lazarillo de Tormes, y de sus fortunas y adversidades. Madrid: Anejos del Boletín de la Real Academia Española, 1967.

CASTRO, Américo. "El Lazarillo de Tormes". Hacia Cervantes. Madrid: Taurus, 1967.

CISNEROS, Luis Jaime. El Lazarillo de Tormes. Buenos Aires: Kier, 1946.

LAURENTI, Joseph. L. Catálogo bibliográfico de la literatura picaresca. Siglos XVI-XX. Kassel: Edition Reichenberger, 2000.

MADRIGAL, José Luis. "Cervantes de Salazar, autor del Lazarillo". Artifara 2 (2003). http://www.artifara.com/rivista2/testi/ cervlazar.asp

NAVARRO DURÁN, Rosa. Alfonso de Valdés, autor del "Lazarillo de Tormes". Madrid: Gredos, 2003.

NÉSPOLO, Matías. "El Lazarillo es de autor valenciano", El Mundo, Sección Cultural, 16 de noviembre de 2007. 
PICASSO MUÑOZ, Julio. "Petronio y Quevedo". Scientia et Praxis 13 (1977): 125-130.

REY HAZAS, Antonio. "Poética comprometida de la novela picaresca". Deslindes de la novela picaresca. Málaga: Servicio de publicaciones de la Universidad de Málaga, 2003. 11-35.

RODRÍGUEZ MANSILLA, Fernando. "La lectura como acto de fe (a propósito de Alfonso de Valdés, autor del "Lazarillo de Tormes” de Rosa Navarro)". Hueso Húmero 45 (2004): $167-174$.

\section{Correspondencia:}

Fernando Rodríguez Mansilla

Profesor del Departamento de Estudios Hispánicos de Hobart and William Smith Colleges, Nueva York.

Correo electrónico: Mansilla@hws.edu 